\title{
Investigation Parallels at University Hospitals: 1950-1975 \\ The Departments of Urology and Obstetrics and Gynecology
}

\author{
Charles E. Hawtrey, MD ${ }^{1}$
}

\begin{abstract}
:
The 1950's was a period of notable intellectual growth and collaboration. During that period new isotopic elements evolved to new treatments for cancer patients, both women and men. The University of lowa proved to be a fertile intellectual community where Gold 198 colloid successfully advanced survival for both ovarian and prostate cancer.
\end{abstract}

Other collaboration expanded the fields of male and female infertility. Both departments benefit from this early pioneering work to the present day.

\section{lowa prostate cancer treatment prior to radioactive gold:}

The historical review paper of prostate cancer patients treated in the 1940's, published by Dr. Rubin Flocks in 1950, demonstrated a life expectancy that was decidedly grim with 2.5-year average survival (Figure 1). Flocks' best outcome data were obtained with transurethral resection and delayed estrogen treatment [4.5 years average survival]. ${ }^{1}$ Similar clinical confirmatory data from the University of Michigan reported by
Dr. Reed Nesbit suggested limited survival among elderly prostate cancer patients. $^{2}$

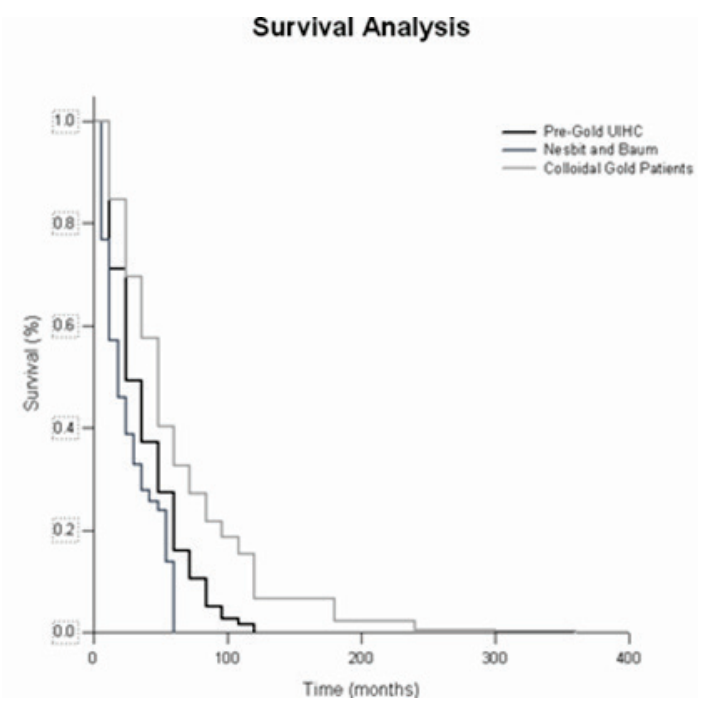

Figure 1: Average survival of prostate cancer patients in the 1940's with different treatments.

Returning to University Hospitals from the Manhattan Project in Oak Ridge Tennessee (1946), Dr. William C. Keettel found useful therapy for ovarian

${ }^{1}$ Professor Emeritus, The Department of Urology, Roy J. and Lucille A. Carver College of Medicine, The University of lowa, lowa City, lowa, USA.

Please cite this paper as: Hawtrey CE. Investigation Parallels at University Hospitals: 1950-1975. The Departments of Urology and Obstetrics and Gynecology. Proc Obstet Gynecol. 2013;3(3 Suppl):Article: 7 [ 7 p.]. Available from: http://ir.uiowa.edu/pog/. Free full text article.

Corresponding author: Charles E. Hawtrey, 200 Hawkins Drive, Department of Urology, lowa City, IA 52240, charleshawtrey@uiowa.edu.

This is an Open Access article distributed under the terms of the Creative Commons Attribution 3.0 Unported License (http://creativecommons.org/licenses/by/3.0), which permits unrestricted use, distribution, and reproduction in any medium, provided the original work is properly cited. 
cancer with colloidal radioactive gold, Au198. The isotope had a relatively short half-life of 2.7 days. Its beta emissions made it ideal for short-term radiation exposure. From the gynecologic literature, it seems reasonable to assume that $\mathrm{Dr}$. Keettel had medical peers at Oakridge who helped him obtain colloidal gold to treat his ovarian cancer patients. Thus, the isotope was available on the day his colleague Rubin Flocks needed a substitute for the radon seeds, which were being used to treat prostate cancer but were unavailable.

\section{Initial observations with radioactive gold and cancer of the prostate:}

When Dr. Flocks became Chairman of Urology (1949-50), he turned to the use of radioisotopes in the treatment of carcinoma of the prostate. ${ }^{3}$ At the end of World War II various radioisotopes became available for study, including Au198 that was used to treat ovarian cancer. ${ }^{4}$ On March 21, 1951, Dr. Flocks injected 60 millicuries of colloidal Au198 into the prostate cancer of an $80 \mathrm{y} / \mathrm{o}$ patient with a large bulky prostate cancer that was refractory to estrogen therapy. The patient had been clinically evaluated in October 1950 at University Hospitals, which revealed a T-3 cancer with seminal vesical involvement.

Radon seeds (the more traditional treatment at that time), which were to be used to reduce the tumor mass, were not available on the patient's day of surgery but radioactive gold (Au198) was. Dr. Flocks made the clinical judgment that treatment was important for this elderly gentleman. Postoperatively, the patient and Dr. Flocks were gratified by the marked shrinkage of the prostatic cancer in response to radio-gold colloid. One-anda-half years later, the patient had no palpable prostate lesion and biopsy demonstrated no cancer. ${ }^{5}$

Thus, the anecdotal clinical patient event led to a clinical series of prostate cancer patients. Retrospective vision reveals that medical literature citations of the seminal Sherman papers about gold colloid from Washington University in St. Louis were different for urology, compared to gynecology or radiology. The first citation by Flocks, Kerr, Elkins, and Culp ${ }^{3}$ referred to the same papers as "Allen, W. M., Bonebrake M. D. and Sherman, A. L. Abstracts of Roentgen Ray Society Meeting St. Louis Mo. 1950". The citation suggests that Flocks knew about the presentation but probably did not have the paper directly available to him as he wrote his paper. Dr. Flocks' narrative style demonstrated that he understood the potential benefits of the gold therapy. Sherman's patient population demonstrated transport of the radio-gold to pelvic regional lymph nodes with sufficient fine distribution to destroy metastatic cancer to nodes.

Initially, Flocks used primarily transperineal injection routes but also explored suprapubic, retropubic, transrectal, and transvesical injections to distribute the radioactive colloidal gold into the cancerous tissue. Dr. Flocks injected colloid gold into 552 patients, varying his injections based on tumor shrinkage response. All these early patients (February 1951 to March 1954) were treated by injection of the colloidal gold into the tumor without removal of prostatic tissue. Individual patients might have from one to seven injections of the radioactive agent at 
variable time intervals. In 1959, Flocks reported on his outcomes with 730 procedures performed in 517 patients treated with a range of 1-7 injections of colloidal gold per patient based on clinical response. ${ }^{8}$

In Dr. Dabney Kerr's view, the outcome for the injection patients suggested that a large population of cancer patients were not being treated. As such, Dr. Kerr had a major impact in Dr. Flocks' decision to change the surgical pattern.

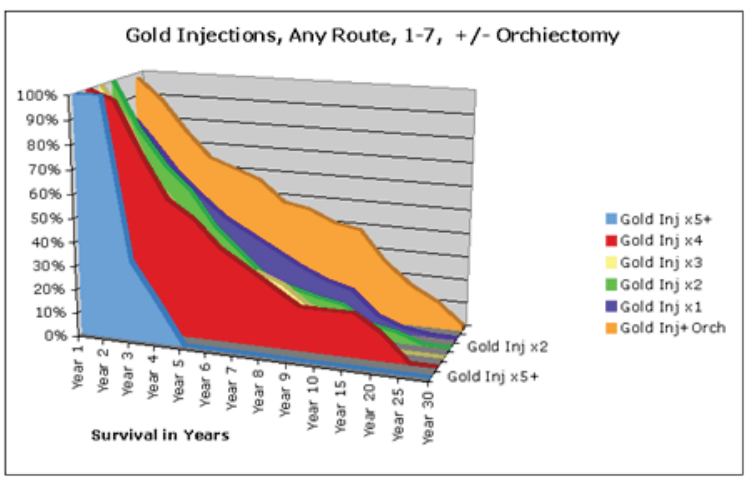

Figure 2: Extended survival with radioactive gold: Flocks kept an elaborate catalogue of all 1515 patients treated over the 25 years of his chairmanship.

\section{Contributions by Raymond George Bunge and James R. Bradbury}

During the Flocks Era, a number of long-term colleagues, research associates, and short term associates joined the clinical faculty, adding additional talent to the department. Clearly Dr. Bunge and Dr. Culp had long and distinguished careers at lowa and their contributions are illustrated below

\section{Dr. Raymond George Bunge, Professor Urology: 1938-1998}

Dr. Bunge was one of those provocative characters who loved to stimulate new thought. He would ask the probing questions, like "how do you know that to be so?" -or - "on what basis do you make such a rash judgment?" $\mathrm{He}$ wanted the urology resident or student to think about the database-the source of knowledge on which a hypothesis was based. As Dr. (Sir) William Osler talked about "brain dusting", Bunge wanted you to think about what you thought you knew and what you did not know in reality. He was clearly a person who thought "outside the box," to borrow modern terminology.

He loved the process of analysisfinding a solution to a clinical problem. He didn't always verbalize his thinking process but was willing to explore the possibilities, moving ever closer to the diagnosis and smiling with deep satisfaction when the appropriate diagnosis was made. Thus, he loved to explore his pet area of expertise: problems of intersex. He coined the term, believing that all the genetic, endocrinologic, phenotypic, and psychic factors had not been explored. While he was clearly aware of Greek mythology and its morphic descriptions, he felt that mythic descriptions were not the solution. His writings on intersex delineate his facile mind.

Ray loved abstract art including that which he created himself. He, like Michelangelo, created images with sexual overtones. Buried in his work might be male genitalia within another image. 


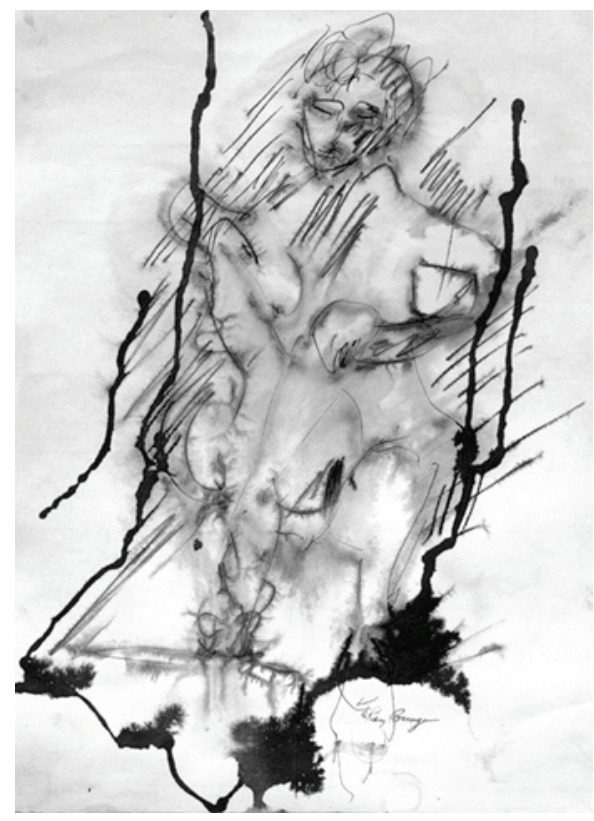

Figure 3: Ink and Water Print, Ray Bunge original

Bunge's first contributions to the urologic literature, upper tract cytology

In 1950, shortly after returning from Army assignments in World War II, Dr. Bunge published three papers on renal upper tract cytology. The first case report represented an unusual intraparenchymal tumor that shed large bizarre multinucleated cells. ${ }^{8}$ This was quickly followed with a series of 11 patients with renal cell cancer, all demonstrating abnormal cytology in retrograde renal pelvis urines. Papanicolaou staining demonstrated the multinucleated renal cells characteristic of the abnormal growth. ${ }^{9}$ By the fall of 1950, Dr. Bunge had identified transitional cell cancer in ureteral specimens and had cultured the transitional cells. ${ }^{10}$ That same year, he wrote a paper on seven patients with various upper tract, ureteral, and bladder transitional cancers that demonstrated the place of urine cytology in diagnosis. He demonstrated that cellular atypia characteristics of the various tumors. ${ }^{11}$ Clearly, like Dr. Flocks, Dr. Bunge had an inquisitive mind and, through collaboration with his peers in Obstetrics and Gynecology, he brought new cytological staining techniques to bear on urologic disease. His interest in cytology continued with the use of triphenyltetrazolium chloride, violet. He found straining in normal renal tissue but not in renal cell cancer, epidermoid cancer or nephroblastoma tissue. Branching out slightly, Dr. Bunge identified and reported a patient with blastomycosis presenting as a prostate infection. Regardless, the examination represented culture and histologic examination of prostatic secretions. ${ }^{12}$ Bunge's collaboration with his resident, Dr. Bill Harness, ${ }^{13}$ led to another case report of an infantile multicystic kidney, a difficult diagnosis in the era before renal ultrasound. The excised surgical specimen proved the diagnosis originally thought to represent a nephroblastoma neoplasm. His extensive output for the medical literature was clearly recognized locally as Dr. Bunge was promoted to full Professor at lowa in the 1952-3 academic years.

Bunge's contributions to urology and male infertility

Dr. Bunge's most profound contributions to the medical literature were in the area of male infertility. In a series of experiments in the 1952-3 period he demonstrated viability in $60-70 \%$ of the cells from ejaculated sperm when the specimen was frozen slowly with dry ice and stored. When such specimens were subjected to freezing suspended in a 
glycerol medium 1 part to 9 of sperm, they retained $50-70 \%$ viability of sperm cells. Moreover, he demonstrated that spermatozoa were unchanged in vital stain characteristics after this freezing process. Using this basic information, by October 1953, Bunge collaborated with Dr. William Keettel in Obstetrics and inseminated four women. Amazingly, he obtaining pregnancies and full term infants in all patients. ${ }^{14}$

These observations "revolutionized" reproductive medicine. He originally submitted the paper to Science, and there was considerable "scientific" controversy between Dr. Bunge and editors for Science. It seemed that missed periods and positive pregnancy, Aschein-Zondek tests, were not sufficient to convince the scientific community of the time that these observations represented a normal pregnancy. One had to see a newborn baby to convince editors that women were really pregnant and carried the baby to term. ${ }^{15}$ In fact, Bunge had submitted the paper to Science in early July 1953 and had active correspondence with its editors who rejected the paper after deliberation. Bunge's observations were ultimately published in Fertility and Sterility. ${ }^{14}$

Ever a man of great humor, Dr. Bunge summarized his clinical work in a letter to his mother. Dr. Bunge wrote: "You tell uncle George that it won't be long before my icicles [frozen sperm specimens] will be in the deep frozen section of the A\&P stores [Atlantic and Pacific Tea Company] and that I probably will not continue to be a doctor but will just supply the huge demand for this material." 16 This one sentence suggested that male infertility had an immediate impact on the medical community and opened the door to artificial insemination for infertile couples. The subspecialty program in male infertility arose from these early clinical observations, in no small part related to Bunge's work. The ethical issues generated by these scientific papers continue to divide society today but were not part of the discussion in these early clinical pilot studies.

Keettel and Bunge provided follow up papers on pregnancy among infertile patients in $1954^{13}$ and $1956 .{ }^{17}$ The reported pregnancies carried to term proved the effectiveness of the technique. Research reproductive physicians could now conceive of storing serial samples of patient's semen to increase the number of sperm in infertile male patients. Sperm specimens were to be placed in an endo-cervical cap at ovulation to assure the most optimal circumstances for conception.

In the late 1950's Dr. Bunge and Dr. James Bradbury collaborated and reported on a child with a chromosomal abnormality of Klinefelter's Syndrome and intra-tubular cells reminiscent of oocytes. ${ }^{18}$ A second paper in 1960 demonstrated the progression of thought to incorporate the intersex states and the induction genital duct development towards either male or female lines. ${ }^{19}$

These collaborative efforts advanced the subspecialties of male and female infertility and the stature of both departments in the medical world. In Urology and Gynecology the fields of male and female infertility have dramatically expanded in the intervening 
$40+$ years. The study of intersex issues anatomic, endocrinological, and psychosocial development has expanded exponentially.

\section{References}

1. Flocks $\mathrm{RH}$, Harness WN, Tudor JM, Prendergast L. Treatment of carcinoma of prostate. Trans South Cent Sect Am Urol Assoc. 1950;57:148-64. PubMed PMID: 13015656.

2. Nesbit RM, Baum WC. Management of occult prostatic carcinoma. J Urol. 1951 May;65(5):890-894.

3. Flocks RH, Kerr HD, Elkins HB, Culp D. Treatment of carcinoma of the prostate by interstitial radiation with radio-active gold (Au 198): a preliminary report. J Urol. 1952 Aug;68(2):510-22. PubMed PMID: 14955881.

4. Elkins HB, Keettel WC. Radioactive gold in the treatment of ovarian carcinoma. Am J Roentgenol Radium Ther Nucl Med. 1956 Jun;75(6):1117-23. PubMed PMID: 13313879.

5. Kerr HD, Flocks RH, Elkins HB, Culp D. The treatment of moderately advanced carcinoma of the prostate with radioactive gold. Am J Roentgenol Radium Ther Nucl Med. 1953 Jun;69(6):969-77. PubMed PMID: 13050863.

6. Sherman AI, Nolan JF, Allen WM. The experimental application of radioactive colloidal gold in the treatment of pelvic cancer. Am J Roentgenol Radium Ther. 1950 Jul;64(1):75-85. PubMed PMID: 15425694.

7. Sherman Al, Bonebrake M, Allen WM. The application of radioactive colloidal gold in the treatment of pelvic cancer. Am J Roentgenol Radium Ther. 1951 Oct;66(4):624-38. PubMed PMID: 14878046.
8. Bunge RG, Kraushaar OF. An early renal malignancy, diagnosed preoperatively. J Urol.1950 Mar;63(3):475479.

9. Bunge RG, Kraushaar OF Abnormal renal cytology. J Urol. 1950 Mar;63(3):464-74.

10. Bunge RG, Stein RJ. Cyto-dynamic properties of urinary neoplasms. I. Cultivation in vitro of transitional cell carcinoma of the ureter. J Urol. 1950 Nov;64(5):646-50. PubMed PMID: 14785072.

11. Bunge RG. Exfoliative cytology of transitional cell carcinoma. J Urol. 1952 May;67(5):740-4. PubMed PMID: 14939390.

12. Bunge RG, Harness WN. Blastomycosis of the prostate: case report. J Urol. 1951 Aug;66(2):263-4. PubMed PMID: 14861950.

13. Bunge RG, Harness WN. Unilateral polycystic kidney in an infant. J Urol. 1951 Jun;65(6):972-5. PubMed PMID: 14841837.

14. Bunge RG, Keettel WC, Sherman JK. Clinical use of frozen semen: report of four cases. Fertil Steril. 1954 NovDec;5(6):520-9. PubMed PMID: 13210484.

15. Bunge, R. G. Correspondence from Wm L. Straus, Jr. to RGB dated 11 August 1953, "For the reasons enclosed the manuscript you submitted to us on June 10 is found unsuitable for publication in SCIENCE and is being returned to you herewith." "The editorial board have read the above paper with interest From a clinical standpoint the report appears somewhat "premature" until the progress of pregnancy and the products of conception have been observed (a baby). " 
16. Bunge, R. G., Letter Dr. Bunge to his mother Mrs. Anne Bunge, dated 22 December 1953.

Correspondence, University of lowa Archives, Main Library, University of lowa, lowa City IA 52242.

17. Keettel WC, Bunge RG, Bradbury JT, Nelson WO. Report of pregnancies in infertile couples. J Am Med Assoc. 1956 Jan 14;160(2):102-5. http://dx.doi.org/10.1001/jama.1956.029 60370012003. PubMed PMID: 13271168.
18. Bradbury JT, Bunge RG. Oocytes in seminiferous tubules. Fertil Steril. 1958 Jan-Feb;9(1):18-25. PubMed PMID: 13501267.

19. Bunge RG, Bradbury JT. Intratubular bodies of the human testis. Trans Am Assoc Genitourin Surg. 1960;52:21-6. PubMed PMID: 13688847. 